\title{
INVESTIGATION OF THE APPROPRIATE COOKING TEMPERATURE FOR FRESHLY HARVESTED MATURE CORN COBS
}

\author{
A. C. Iheonye ${ }^{1}$, S.N. Asoegwu ${ }^{2}$, K.N. Nwaigwe ${ }^{3}$ \\ ${ }^{I}$ Department of Agricultural Engineering, Federal University of Technology, Owerri, Imo State, Nigeria \\ iheonyeac@yahoo.com \\ ${ }^{2}$ Department of Agricultural Engineering, Federal University of Technology, Owerri, Imo State, Nigeria \\ asosab49@yahoo.com \\ ${ }^{3}$ Department of Agricultural Engineering, Federal University of Technology, Owerri, Imo State, Nigeria \\ kevin_nwaigwe@yahoo.com
}

\begin{abstract}
The investigation of the appropriate cooking temperature for freshly harvested mature corn cobs is presented. The process of Combination cooking method was utilized in the experimentation to ensure the achievement of the appropriate temperature and duration for the cooking stage. The appropriate cooking temperature and duration was found to be $195^{\circ} \mathrm{C}$ and 30 minutes respectively. Variations in initial moisture content of the freshly harvested cobs $(69.7-85.3 \% \mathrm{wb})$ did not affect the cooking temperature and duration. Cooking at the determined appropriate temperature and duration resulted in a properly cooked corn cob.
\end{abstract}

Keywords: Browning; Fresh Corn; Cooking Temperature; moisture content

\section{INTRODUCTION}

Uniformity of browning affects people's decision on which roasted cob they accept or reject (Iheonye, 2015). Most are naturally attracted to roasted corn that comes out "golden yellow" in appearance and properly cooked. Properly cooked grains cannot be assessed visually, so customers are left to play the game of luck while choosing which corn cob to purchase (Iheonye, 2015).

But going by the way corn is roasted locally in Nigeria, over a drum of hot charcoal (charcoal pot), with temperature that cannot be accurately regulated or precisely set, producing roasted cobs that are uniformly browned and properly cooked becomes a problem.

Most times in order to avoid over-browning or charring of the corn cob, it is prematurely removed from the coal pot, only to be later termed undercooked. With this the corn cob is not uniformly browned and properly cooked corn.

Roasting is a cooking method that uses dry heat, whether an open flame, oven or other heat sources (Blaisdell, 2002). The roasting process enhances the flavour and appearance of a product through Maillard browning and caramelization (Fellows, 2000). Roasting and baking are essentially the same unit operation; they both use heated air to alter the eating quality of foods. Fellow (2000) posits that the terminology differs in common usage; baking is usually applied to flour-based foods or fruits, and roasting to meats, nuts, grains and vegetables.
Roasting involves simultaneous heat and mass transfer; heat is transferred into the food from hot surfaces and air in the oven and moisture is transferred from the food to air that surrounds it and then removed from the oven. In the oven, heat is supplied to the surface of the corn cob by a combination of infrared radiation from the oven walls, by convection from circulating air and by conduction through the pan or rack on which the corn cob is placed. For Fellows (2000), infrared radiation is absorbed into the corn cob and converted to heat while air, other gases and water vapour in the oven transfer heat by convection.

The heat is converted to conductive heat at the surface of the corn cob. A boundary film of air acts as a resistance to heat transfer into the corn cob and to movement of water vapour from it. The thickness of the boundary layer is determined mostly by the velocity of the air and the surface properties of the corn cob and in part controls the rates of heat and mass transfer (Fellows, 2000). Convection currents promote uniform heat distribution throughout the oven (necessary for proper cooking and uniform browning of corn cobs), and many commercial designs are fitted with fans to supplement natural convection currents and to reduce the thickness of boundary films. This increases heat transfer coefficients and improves the efficiency of energy utilisation by the corn cob.

In contrast with dehydration, where the aim is to remove as much water as possible with minimal changes in sensory quality, in roasting the heat-induced changes at the surface 
of the food (browning) and retention of moisture in the interior of some products (cake, bread, meats, roasted corn, etc) are desirable quality characteristics. Roasting a corn cob in a convective oven would produce corn that browns uniformly on all side and has well-cooked grains (Iheonye, 2015).

Fellows (2000) stated that the energy consumption during roasting is of the order of 450-650 kJ per kilogram of food. Most of the heat is used to heat the food, to evaporate water, to form the crust, to superheat water vapour (steam) that is transported through the crust and to heat the dry crust.

According to Blaisdell (2002), there are several plans for roasting food stuff depending on the food, its size and the taste of the people. The plans are as follows:

i. Low temperature cooking method

ii. High-temperature cooking method

iii. Combination cooking method

Of these, the best method is the Combination cooking method, made up of two stages - cooking phase and browning phase (Blaisdell, 2002). During the cooking phase the grains are properly cooked then uniformly browned during the browning phase.

Corn roasting is a unit operation in food processing with measurable parameters that are investigated, determined and controlled throughout the process of roasting to produce properly cooked and uniformly browned cobs. The parameters that would bring about proper cooking during the cooking phase are temperature of cooking and cooking duration while those that affect browning are temperature, duration of heating, $\mathrm{pH}$, water activity (Carabasa-Giribet and Ibarz-Ribas, 2000).
If these parameters are maintained at appropriate levels during the roasting process, we would always have finished products that are properly cooked and uniformly brown in appearance.

This research work is devoted to investigating the appropriate temperature and duration needed to properly cook freshly harvested corn cobs during the cooking phase. This would ensure that the corn is properly cooked before browning is initiated.

\section{MATERIALS AND METHODS}

\subsection{Equipment/Instruments}

The equipment used for the experiment are stated below: Electronic weighing balance (maximum weight $=5 \mathrm{~kg}$; linearity error $=0.005 \mathrm{~kg})$

Convective Oven (Electrolux 30" Gas Slide-in range with Wave-Touch ${ }^{\circledR}$ control - Model EW3ØGS65GS)

Six rolls of $8 \mathrm{~m} \times 0.45 \mathrm{~m}$ aluminum foil

4 pieces of $1.3 \mathrm{~m}$ long $1 \mathrm{~mm}$ copper twine

2 Kitchen knives

2 pieces of $3 / 2$ " baking brush

\subsection{Oven Selection}

The oven used was the Electrolux ${ }^{\circledR} 30$ " Gas Slide-in range with Wave-Torch ${ }^{\circledR}$ control - Model EW3ØGS65GS. It is built with a Perfect Convert3® technology, which features a third convection element (350watts) and centrifugal fan that circulates heat evenly throughout the oven, thus providing near isothermal cooking conditions during the cooking phase.

Other features of the oven that were relevant to the research work are stated below (Electrolux, 2010).

Table 1.Features of the Electrolux ${ }^{\circledR} 30$ " Gas Slide-In Range

\section{ELECTROLUX® 30" GAS SLIDE-IN RANGE}

Control Panel Features

\begin{tabular}{|c|c|}
\hline IQ-Touch ${ }^{\mathrm{TM}}$ Electronic Oven Control & Yes \\
\hline Keypad Entry of Time and Temperature & Yes \\
\hline Electronic Clock and Timer & Yes \\
\hline Temperature Display & Yes \\
\hline \multicolumn{2}{|l|}{ Oven Features } \\
\hline Capacity & $4.2 \mathrm{Ft}^{3}$ \\
\hline Hidden Bake Burner & Yes \\
\hline Bake Burner - 18,000 BTU & Yes \\
\hline Convection Element - 350Watts & Yes \\
\hline Cobalt Blue Interior & Yes \\
\hline Perfect Convect ${ }^{3} \AA$ with variable 2 -Speed Fan & Yes \\
\hline Convection Roasting Rack & Yes \\
\hline Lighting with Dual 40W halogen bulbs & Yes \\
\hline
\end{tabular}




\subsection{Sample Collection and Preparation}

Fresh corn cobs (with a 90-days maturity period) were harvested soft and milky from a farm at Avu, Imo state, Nigeria, to be used immediately for the cooking phase. Before introducing a cob into the convective oven, its husk was slit through (longitudinally) from up to bottom at opposite sides of corn cob. This was to ensure easy detachment of the cob from its base without disintegrating the husk, which would be used as housing for the cob during the cooking process. Upon detaching the cob from its base, a small portion of the cob $5-7 \mathrm{~cm}$ long was cut out from the top (slimmer) portion of the cob. This small portion was used to determine the initial moisture content ( $w b)$ of the corn cob. The initial moisture content of the corn cob was calculated as a percentage of the initial moisture content of the smaller portion. The initial moisture content of the smaller portion was calculated thus (Karoly, 2006):

$$
M C(w b)=\frac{M_{d}}{M_{w}} \times 100 \%
$$

Where

$$
\begin{aligned}
& \text { Md = Mass dry sample in grams (after drying) } \\
& \text { Mw = Mass of wet sample in grams (before drying) } \\
& M C(w b)=\text { Moisture content of decapitated sample }
\end{aligned}
$$

in wet basis

Afterwards, the weight of the bigger portion of corn cob and the husk were noted. The total weight of the corn cob was calculated as the sum of the weights of the smaller and bigger portions respectively.

The bigger portion of the corn cob was then re-introduced into the husk, tied up with $1 \mathrm{~mm}$ copper twine (1.3m long) and wrapped with aluminum foil. These were done to reduce water loss during the cooking phase and increase the vapour pressure and temperature of steam generated from the moisture within the husk, thereby reducing the time needed to properly cook the grains.

After wrapping the corn cob in the husk and aluminum foil, their collective weight were also recorded. The samples were ready for the cooking phase.

\subsection{Cooking the Corn Cob}

The first phase (cooking phase) of the Combination cooking method was used. Before introducing the un-dehusked cob into the convective oven for cooking, the oven was preheated to a selected test temperature. Upon attaining the desired temperature, the un-dehusked corn sample was introduced into the oven for cooking. The corn sample was brought out of the oven every 10 minutes to confirm if its grains were properly cooked but not case hardened. The assistance of a 5-member sensory evaluation panel was used to determine a properly cooked corn cob.

Prior to inspecting a corn cob, the aluminum foil was carefully unfolded, the twine removed, and cob removed from within the husk. In addition to checking if the cob had cooked, the combined weight of the cob, husk, foil and twine were also noted. The difference between this combine weight and the weight of the foil and twine alone gave the weight of the husk and cob per cooking duration. The reduction in the combine weight recorded every 10minutes was an indication of water loss.

After inspection and measurement were taken, the cob was put back into its husk, tied with the twine then wrapped in the aluminum foil before cooking it in the oven for another 10minutes, after which, the sample was brought out, weighed and inspected. This 10 minutes cooking then inspection process was repeated till it was agreed that the sample had properly cooked.

This process was carried individually for fifteen (15) undehusked corn cobs cooked at 150, 155, 160, 165, 170, 175, $180,185,190,195,200,205,210,215$ and $220 \mathrm{oC}$ respectively.

At the end, the temperature and duration that brought about proper cooking of the corn cob without case hardening the grains was chosen as the appropriate cooking temperature and duration.

\section{RESULTS AND DISCUSSION}

Figure 1 shows a graphical relationship between cooking temperature, appropriate cooking duration and the initial moisture content for 15 corn samples (B1 - B15) 


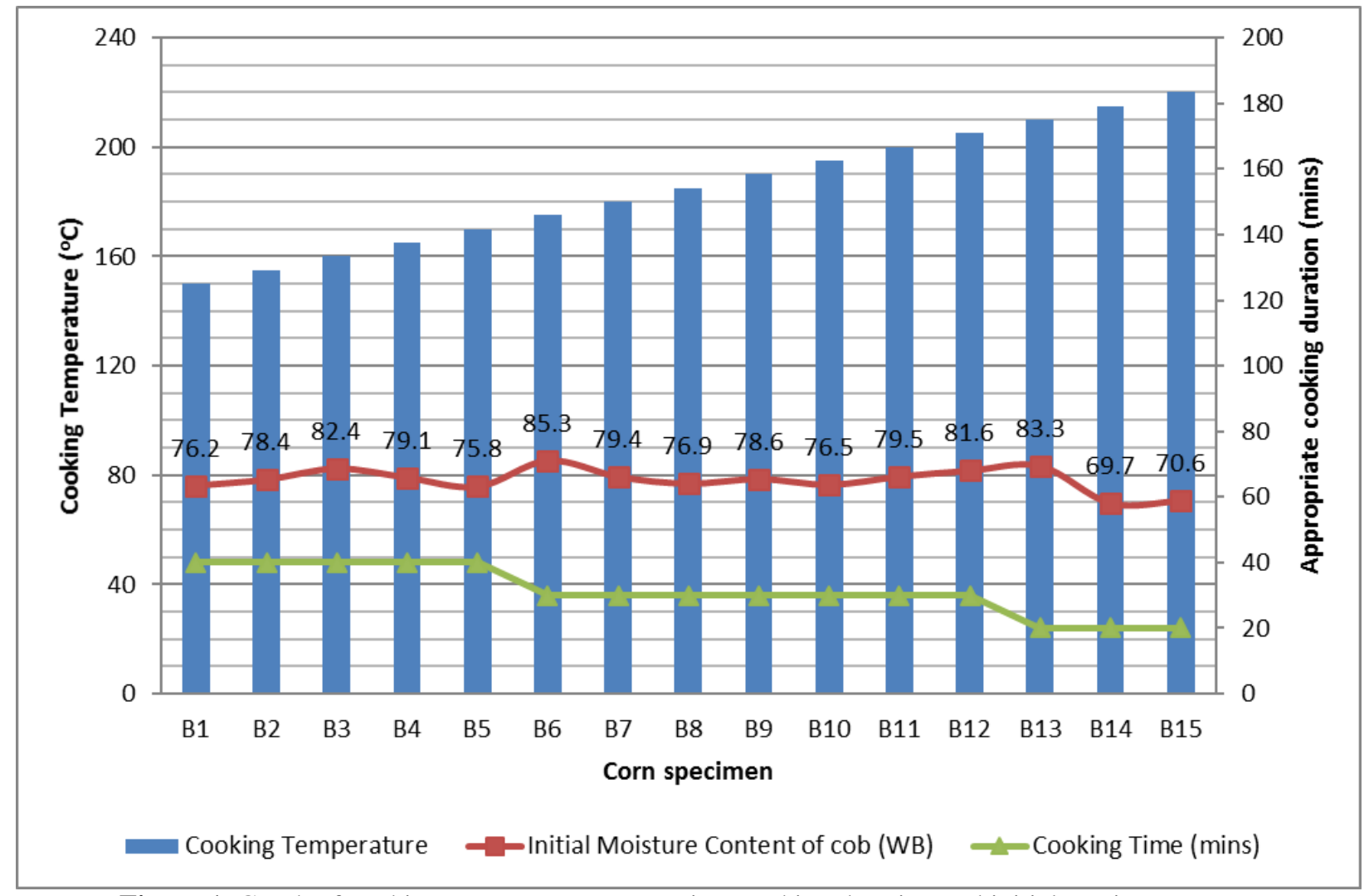

Figure 1. Graph of cooking temperature, appropriate cooking duration and initial mositure content

As shown above, variations in the initial mositure content (wb) of the freshly harvested cob samples ranging from 69.7 $-85.3 \%$ did not affect the values of the appropriate cooking time. This could be as result of intake of water by the grains during the cooking process. As shown on Figure $1 \& 2$, corn cobs cooked at temperatures $150 \mathrm{oC}-170 \mathrm{oC}$, required 40 minutes for proper to cooking to be achieved. Cobs cooked at temperatures $175 \mathrm{oC}-200 \mathrm{oC}$ required 30 minutes while does cooked at $2050 \mathrm{C}-220 \mathrm{oC}$ were properly cooked at 20 minutes. The reduction in cooking duration when cooking temperature was increased could be as a result of increase rate of sugar/starch gelatinsation within the corn grains due to increase in cooking tempeature.

It was observed by the five member sensory evaluation panel that the cob specimen cooked at $195 \mathrm{oC}$ had a sweeter (sugary) taste than the others. This was reconfirmed with two repeat tests. Therefore, $1950 \mathrm{o}$ was chosen as the appropriate cooking temperature for freshly harvested corn cob (90days maturity period).

Figure 2 shows a trendline relationship between the cooking temperature and appropriate cooking duration.

The equation of the trendline that best fits the experimental graph was a 6 order polynomial of the form:

$y=a+b x+c x^{2}+d x^{3}+e x^{4}+f x^{5}+g x^{6}$

(2)

Where

$\mathrm{y}=$ Appropriate cooking duration (minutes)

$\mathrm{x}=$ Cooking Temperature
Using Microsoft excel ${ }^{\mathrm{TM}}$ and CurveExpert Professional ${ }^{\mathrm{TM}}$ the following values were determined:

$a=1.190678 \times 10^{6}$

$b=-3.996197 \times 10^{4}$

$c=5.564821 \times 10^{2}$

$d=-4.115212$

$e=1.704485 \times 10^{-2}$

$f=-3.749200 \times 10^{-5}$

$g=3.421626 \times 10^{-8}$

With coefficient of determination $\left(R^{2}\right)=0.9490786$ Substituting the constants (a-g) into equation 2 we have equation 3 


\section{$y=1.190678 \times 10^{6}-\left(3.996197 \times 10^{4}\right) x+\left(5.564821 \times 10^{2}\right) x^{2}-$ $4.115212 x^{3}+\left(1.704485 \times 10^{-2}\right) x^{4}-\left(3.749200 \times 10^{-5}\right) x^{5}+(3.421626 \times$ $\left.10^{-8}\right) x^{6}$}

Applying the values for y in equation 3, for cooking temperatures between 150 to 220 oC produced Table 2 which compares the experimental cooking temperature to the calculated appropriate cooking duration for freshly harvested corn cobs having an initial moisture content range of $69 \%$ to $85 \%$ (wb).

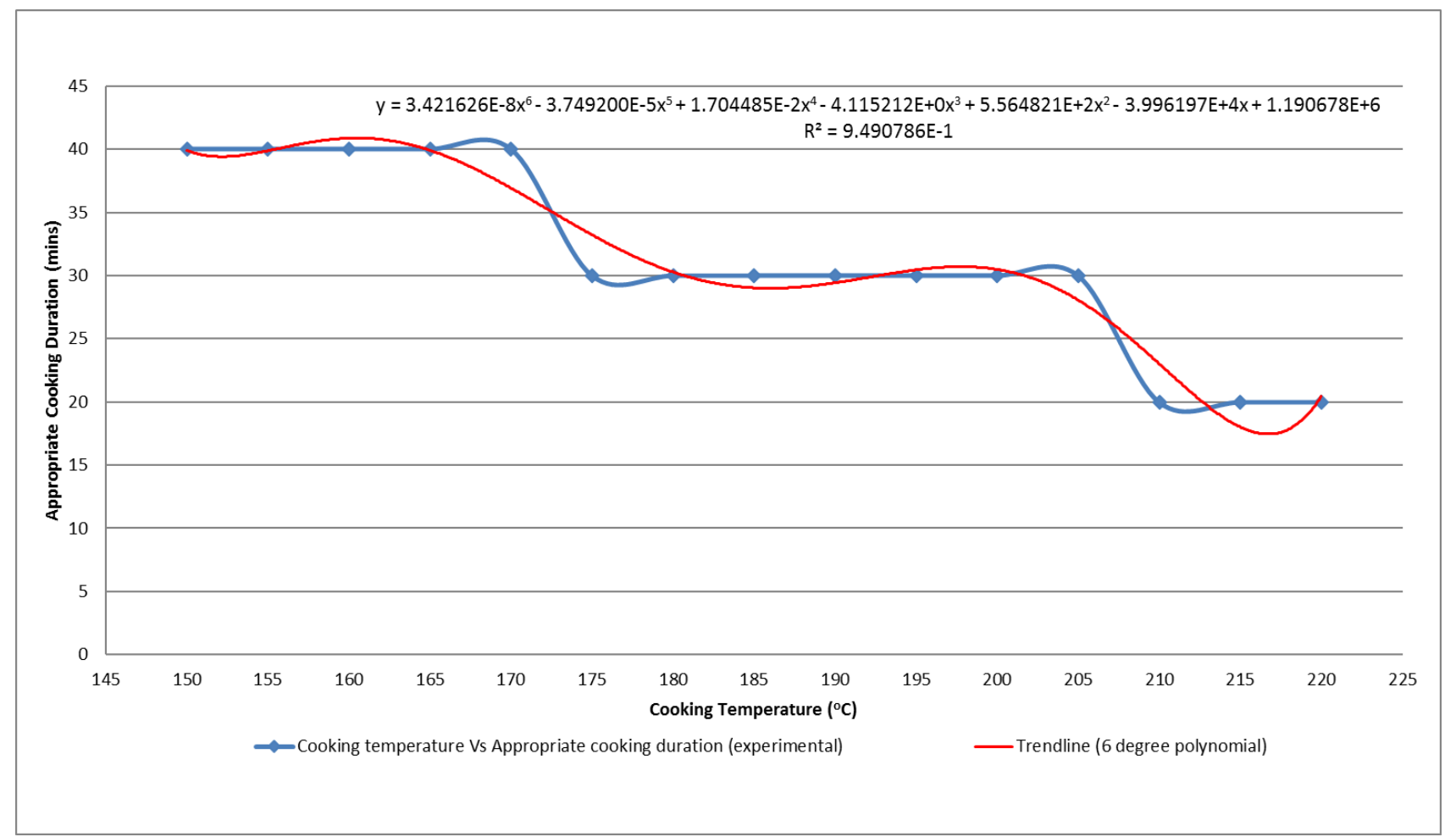

Figure 2. Trendline relationship between cooking temperature and approriate cooking duration

Table 2. Comparisom between Experimental and Calculated appropriate cooking durations

\begin{tabular}{|c|c|c|c|}
\hline \multirow{2}{*}{ Cooking Temperature $\left({ }^{\mathbf{0}} \mathbf{C}\right)$} & \multicolumn{3}{|c|}{ Appropriate Cooking Duration (minutes) } \\
\cline { 2 - 4 } & Experimental & Calculated & Change \\
\hline 150 & 40 & 40.40 & $1.00 \%$ \\
\hline 155 & 40 & 40.45 & $1.11 \%$ \\
\hline 160 & 40 & 41.55 & $3.87 \%$ \\
\hline 165 & 40 & 40.72 & $-5.31 \%$ \\
\hline 170 & 40 & 37.87 & $14.39 \%$ \\
\hline 175 & 30 & 34.32 & $5.15 \%$ \\
\hline 180 & 30 & 31.55 & $1.62 \%$ \\
\hline 185 & 30 & 30.49 & $3.65 \%$ \\
\hline 190 & 30 & 31.10 & $7.85 \%$ \\
\hline 195 & 30 & 32.35 & $8.80 \%$ \\
\hline 200 & 30 & 32.64 & $1.62 \%$ \\
\hline 205 & 30 & 30.49 & $28.66 \%$ \\
\hline 210 & 20 & 25.73 & $5.25 \%$ \\
\hline 215 & 20 & 21.05 & $19.30 \%$ \\
\hline 220 & 20 & 23.86 & \\
\hline
\end{tabular}




\section{CONCLUSIONS}

The findings of this study showed that the appropriate cooking temperature and duration for freshly harvested corn cob (90 days maturity period) was found to be $1950 \mathrm{C}$ for 30mins. This produced properly cooked and soft corn cobs. Furthermore, the initial mositure content (wb) of the freshly harvested cob samples used in this work ranged from 69.7 $85.3 \%$ and had no effect on the cooking time.

An equation (a 6-order polynomial) with R2 $=0.949$, was developed to show the relationship between the cooking temperature and appropriate cooking duration for freshly harvest cob with an initial moisture content of 69.7 to $85.3 \%$.

\section{REFERENCES}

[1] Blaisdell, S. (2002) 'An Illustrated Guide to Beef Roasts', in Kimball, C. (ed.) Cook's Illustrated, Available: http://en.wikipedia.org/wiki/roasting [27 May 2014].

[2] Carabasa-Giribet, M. and Ibarz-Ribas, A. (2000) 'Kinetics of colour development in aqueous fructose systems at high temperatures', Journal of Science of Food and Agriculture, vol. 80, no. 14, November, pp. 2105-2113.

[3] Electrolux (2010) Use \& Care Guide: Gas Slide-In Range, Georgaia, USA: Electrolux Major Appliance, Inc.

[4] Fellows, J.P. (2000) Food Processing Technology Principles and Practice, 2nd edition, Cambridge: Woodhead Publishing Limited.

[5] Iheonye, A.C. (2015) Investigation of the appropriate physical conditions for achieving uniform maillard browning on roasted fresh mature corn (Unpublished M.Eng Thesis), Owerri: Federal University of Technology, Owerri.

[6] Karoly, M. (2006) 'Experimental Techniques in Drying', in Mujumdar, A.S. Handbook of Industrial Drying, 3rd edition, Taylor \& Francis Group, LLC. 